\title{
Early medieval garnet-inlaid metalwork: A comparative analysis of disc brooches from early Wessex
}

Helena Hamerow: Institute of Archaeology, University of Oxford, 34-6 Beaumont Street, Oxford OX12PG. Email: Helena.hamerow@arch.ox.ac.uk

Andrew Shortland: Cranfield Forensic Institute, Cranfield University, Defence Academy of the United Kingdom, Shrivenham, Swindon SN6 8LA, UK. Email:

a.shortland@cranfield.ac.uk

Esther Cameron: 36 Bertie Road, Cumnor, Oxford OX2 9PS. Email:

Esthercameron.oxford@gmail.com

\begin{abstract}
Garnet inlaid metalwork was an emblem of elite culture in the early medieval North Sea world. This study compares three Anglo-Saxon garnet-inlaid brooches that are exceptionally similar in design and appearance. All three date to the seventh century, a period that saw the emergence of leading families that used such deluxe dress items to enhance their political position. The central hypothesis explored here is that the brooches were produced by the same, or by closely linked, goldsmiths working under the patronage of such a family. Integrated analysis was conducted using microscopy, CT scans, XRF and XRD, in part to establish whether the garnets used came from the same or different sources.
\end{abstract}

\section{Introduction}

Garnet inlaid metalwork was one of the most striking emblems of elite culture in the North Sea zone during the fifth to seventh centuries. This study compares three Anglo-Saxon garnet-inlaid disc brooches that display exceptionally close similarities in appearance and design (INSERT Fig 1 HERE). All three date to the seventh century, a period that saw the emergence of leading families that used deluxe dress items such as these to enhance their political position through gift-giving and competitive display. ${ }^{1}$ The central thesis explored in this paper is that the three brooches - found in two cemeteries in the Upper Thames Valley were produced by the same, or by closely linked, goldsmiths, working under the patronage of such a family. To address this question, integrated analysis of the brooches was conducted using microscopy, computed tomography scans, X-ray fluorescence and X-ray diffraction analyses (hereafter, CT, XRF and XRD), and a simple method for establishing whether the

\footnotetext{
${ }^{1}$ Hamerow 2017
} 
garnets used came from the same or different sources was applied (see below, 'Analysis of Materials'). The results demonstrate the potential of such integrated analysis to shed light on the patronage of craft production and, more specifically, on the circulation of garnets.

Two of the brooches come from burials in a poorly recorded cemetery at Milton, Oxfordshire while the third was found by a metal detector user in an apparently isolated burial lying less than $10 \mathrm{~km}$ to the West, at West Hanney, Oxfordshire. ${ }^{2}$ Both sites lie in the Upper Thames valley, the early heartland of the kingdom of the West Saxons who, at this early date, were known as the Gewisse. ${ }^{3}$ The great majority of composite disc brooches some 23 complete or largely complete examples of which have been recorded at the time of writing - come from Kent, where this opulent brooch type was first developed and where it was most frequently worn (INSERT Fig 2 HERE). Kent is still regarded as the main entry point for the gold and garnets used to make such objects, although there may have been other entry points along the eastern and southern English coasts. ${ }^{4}$

In terms of design and dimensions, the Milton and Hanney brooches are exceptionally closely linked. This becomes clear when they are compared to other composite disc brooches with copper alloy, rather than gold, cloisons; all are thought to date to the middle decades of the seventh century (INSERT Fig. 3 HERE). ${ }^{5}$ As Figure 3 shows, such brooches vary considerably in size and design, although all display a cruciform layout emphasized by white bosses. The brooches from Milton and West Hanney - all approximately $74 \mathrm{~mm}$ in diameter stand out as forming a coherent group in terms of both design and dimensions. The discovery of three such similar brooches within $10 \mathrm{~km}$ of each other raises the possibility that they were made not in Kent but locally. If so, this suggests some connection between the households for whom the brooches were made.

Traditionally, the existence of early Anglo-Saxon workshops has been inferred largely on the basis of similarities in the style and design of ornamental metalwork, above all brooches; materials and manufacturing techniques are relatively uninformative in this respect since the overwhelming majority of brooches from this period consists of single pieces of cast copper alloy, a material which was itself extensively recycled. ${ }^{6}$ Disc brooches, however, because of their composite nature and use of a range of materials, offer the possibility of

\footnotetext{
2 Hamerow 2015

3 Blair 1994; Hamerow, Ferguson and Naylor 2013

${ }^{4}$ Huggett 1988; Hamerow 2017

${ }^{5}$ Avent 1975; Scull 2009, 90

6 Speake 1980; Dickinson 1993; Lucy 2000; Leahy 2011; Pollard, Bray and Gosden et al 2015
} 
assessing degrees of similarity through the materials and techniques used in their manufacture, as recognized by Coatsworth and Pinder. ${ }^{7}$ An initial comparison of the three brooches suggested, on the basis of similarities in design and method of construction, that all three had probably been made in the Upper Thames Valley, with the two from Milton having in all likelihood been produced by the same goldsmith(s). ${ }^{8}$ The Hanney brooch displays certain differences in technique and style of execution that suggest it may have been the work of one or more different specialists who were, nevertheless, clearly referencing the Milton brooches. ${ }^{9}$ In the present study, the results of technological and compositional analysis of the brooches undertaken at the Cranfield Forensic Institute are presented and the implications for understanding how such objects were produced are explored.

As noted above, the Milton and Hanney brooches are closely related in terms of design and overall appearance. Our aim was to establish the extent to which this similarity in appearance is reflected in the techniques and materials used in their construction. Our investigation established a 'profile' of each brooch based on the quality of workmanship, the method of construction and the materials used. These profiles were then compared to assess degrees of inter-relatedness. In the following sections, the construction and craftsmanship involved in the production of the brooches are compared, followed by an analysis of the materials used.

\section{Analysis of Construction and Craftsmanship}

The Hanney brooch and one of the Milton brooches ${ }^{10}$ were examined using binocular microscopy at magnification up to 50X. This revealed no tool marks suitable for SEM analysis. ${ }^{11}$ Detailed observations relating to the design, construction and craftsmanship of the brooches are supplied in Appendix 1. From these, a list of 33 attributes was compiled, some of which are shared by all three brooches, some by two and some of which are unique to one. The results were plotted on a Venn diagram as a means of displaying the similarities and differences between all three (INSERT Fig 4 HERE).

The diagram reveals that features common to all three brooches are: rows of pentagonal garnets, the radii of the second and third concentric rings and of satellite rivets,

\footnotetext{
7 Coatsworth and Pinder 2002, 171

8 Hamerow 2015, 100-101

9 Hamerow 2015: 100-101

10 Ashmolean Museum acc. no. 1836 p.123 no.59

11 Larsen 1987; Goodburn-Brown 1988
} 
beaded-wire filigree, gridded gold backing foils with 4 lines per mm grid, safety loops and Avent's Type 5 fastenings. The CT scan of the Hanney brooch (Appendix 1) further revealed that the copper alloy plate forming the middle layer of the brooch was marked out using the same proportions as those of the top plate of one of the Milton brooches, ${ }^{12}$ suggesting that the same template was used for both. More significantly, CT scans revealed that the radii of the second and third concentric rings, and the radius of the circle on which the rivets are positioned, was identical in all three brooches, again indicating use of a shared template (Appendix 1, Table 2). Figure 4 also shows, however, that the two Milton brooches share several attributes not shared by the Hanney brooch. These are the use of small four-sided garnets, Style II interlace, gold mounts with a high level of craftsmanship, modelling and surface enrichment, white domes made of bone, convex base-plates, iron rivets, waxy white paste (INSERT Fig 5a, 5b HERE). Neither of the Milton brooches shares an attribute with the Hanney brooch that is not also shared with the other.

Differences between the two Milton brooches are limited: small rectangular gold mounts are found on the Ashmolean brooch, but not on the other, ${ }^{13}$ and the circumferential collars of the two brooches are made differently despite looking the same. The Hanney brooch, on the other hand, has a relatively large number of attributes which do not occur in either of the other two. These are: large four-sided garnets, round-wire filigree, S-scrolls, gridded gold backing foils with 3.2 lines per mm ('box grid'), white domes made of shell, a flat base-plate, an extra plate above the base plate, copper-alloy rivets, non-waxy white paste, engraved decoration on the back, and a medium to low level of craftsmanship in the gold mounts. Some apparent differences, for example in the presence/absence of cabochon garnets and crown arches, may simply be due to incomplete survival.

\section{Analysis of Materials}

Methods Used

Micro-CT and XRF .

Analysis of the three brooches was carried out in the laboratories of Cranfield Forensic Institute, Cranfield University. It was imperative that the brooches were not damaged or

\footnotetext{
12 Ashmolean Museum acc. no. 1836 p.123 no.59. The CT scans were undertaken using a Nikon XT H 225 micro-scanner with a transmission target. Data was reconstructed using CT Pro 3D software, and processed with VG Studio Max 2.1 software.

13 Victoria and Albert Museum (V\&A) acc. no. M109=1939
} 
sampled in any way, which dictated the techniques used. Two were chosen, microtomography (micro-CT) and X-ray fluorescence (XRF). It is important to consider the possibilities and limitations of these techniques in order to interpret the results correctly.

Micro-CT is an X-ray imaging technique with the potential to produce highresolution, three-dimensional images of objects, with the grey scale on the image revealing something of the relative X-ray opacity of the material involved; the darker the material, the more X-ray opaque and therefore dense it is. This clear pattern can be influenced and potentially confused by variations in thickness of the material and other edge effects caused by shadowing of the X-rays. However, this technique is a relatively quick and nondestructive way of examining the internal structure of an object; from this, one can infer how it might have been constructed.

$\mathrm{XRF}$ is a surface technique that gives a qualitative analysis of the surface of an object to the depth of a few tens of microns. The quality of the analysis is constrained by several factors, some of which are inherent to all XRF analysis and some that are specific to certain materials and objects. The analysis of the brooches was carried out in a benchtop XRF system, in an air environment. The presence of air in the chamber attenuates low energy Xrays, meaning that it is usually impossible to detect elements lighter than silicon. This means that elements such as sodium, magnesium and aluminium are, at best, difficult to detect. The morphology of the target also has an effect on the quality of the analysis. The brooches are not flat, and have large bosses and other features that protrude from the surface. These meant that the analyses had to be carried out at double or triple the standard working distance of $10 \mathrm{~mm}$. This compounds the issue with the attenuation of low energy X-rays, simply because the X-rays have further to travel through the air. Secondly, the targets were sometimes not flat on a microscopic scale. This means that the analysis area might contain a dip or hump, or the whole area might be slightly raked. In severe cases this can cause problems, but experimental work on the instrument used in this analysis has shown that, within the limits of a qualitative analysis, minor undulations in the surface have very little impact on the reliability of the results. ${ }^{14}$

Further problems can be created by the material types being analysed. In this case, two types of problem arise, each of which presents its own challenges. The first type applies to the garnets. Garnets are in effect single crystals on a microscopic scale, which means that in addition to the normal fluorescence peaks given off by interaction with the X-ray beam,

${ }^{14}$ Domoney 2012 
occasionally diffraction peaks can also be created. These single or multiple sharp peaks can appear anywhere in the analytical spectrum and are usually easy to identify. However, very occasionally, they may overlap exactly with a large fluorescence peak, rendering them invisible. When determining peak areas to give an idea of how much of an element might be present, this superposition of peaks can give the data more scatter than there really is. However, as long as the data is taken qualitatively and interpretation is only aimed at distinguishing garnets that are very different from one another, this is not a significant problem. Perhaps more problematic is the second issue concerning the analysis of metal-the gold and copper alloys used in these brooches. It is well known that surface enrichment of certain elements occurs in alloys. This means that in practice, the surface (which is analysed by the XRF) might not be representative of the bulk of the metal. Not only that, but different production techniques and/or burial environments might lead to different levels of surface enrichment. This could mean that two metal objects made from the same raw material might look compositionally different under the XRF. However, two spectra that look the same are most likely to be the same.

\section{Results}

Garnets

$\mathrm{XRF}$ analysis was used to establish the ratios of four diagnostic elements common in garnets and known to be variable: iron, titanium, manganese and chrome. Analysis of as many of the garnets as time allowed - all 112 of the surviving garnets from the Hanney brooch, 23 from the Milton/Ashmolean brooch and 28 from the Milton/V\&A brooch - was carried out. The elements are shown as ratios of counts per second, rather than weight percent or parts per million. No attempt has been made to calibrate the counts as this tends to be a difficult and often controversial procedure with XRF analyses. However, it is widely acknowledged that XRF can produce excellent, consistent data. This makes it very good at sorting targets, in this case garnets, into compositional groups. The ratios of counts per second of two elements ( $\mathrm{Fe} / \mathrm{Ti}$ and $\mathrm{Cr} / \mathrm{Mn}$ ) is taken because this smooths out small inconsistencies that might be introduced into the data if the samples are not quite at the perfect height or not quite flat. This could affect the absolute number of counts for all the elements in the particular analysis, but it is likely to affect the relative amounts (the ratio of the elements) far less. This gives the best qualitative picture of how the analyses are related and is shown in Figure 6 (INSERT fig 6 HERE). 
[INSERT fig. 7 HERE]. Plotting the analyses for the garnets from the three brooches shows clear variations that form two distinct groups, with some outliers. The groups represent garnets with similar compositions: the larger group which we have called 'Group A', with a relatively high $\mathrm{Cr} / \mathrm{Mn}$ ratio and low $\mathrm{Fe} / \mathrm{Ti}$, and the smaller Group B with the opposite. There is some scatter to the data which might imply subgroups, but given the diffraction peak issues discussed above, it is safer to regard the data as representing two main groups. All the garnets from the Milton/Ashmolean brooch belong to 'Group A'. It is reasonable to infer that they derive from the same source. The garnets from the Milton/V\&A brooch are similar, with all except one garnet falling into the 'Group A' composition. Again, it is reasonable to consider that (with one exception) they come from one source. Given the compositional, stylistic and geographical relationships of the two brooches, one might reasonably infer that all the Group A garnets from these brooches come from the same source. 'Source', in the sense used here, implies a cohesive geological unit with garnets of relatively uniform composition. This unit could be highly localized (e.g. from one small quarry) or could stretch across tens or even hundreds of square kilometres. The aim here was to distinguish between different compositional types by means of relatively quick, simple non-destructive analysis, rather than to establish the geographical location of the garnet source. It should be acknowledged that it is possible for two distant and unrelated garnet sources to have the same compositional signature. Nevertheless, given the stylistic and technical links between the three brooches, all made in England at around the same time, it is most unlikely that the compositional similarities between the garnets are coincidental, i.e. that the garnets derive from two compositionally identical but unrelated sources.

The West Hanney Brooch is more complex. It too contains a group of Type A garnets, relatively high and variable in $\mathrm{Cr} / \mathrm{Mn}$, and low and consistent in $\mathrm{Fe} / \mathrm{Ti}$ ratio, but also has a significant number of garnets with other compositions. The largest of these is a relatively diffuse group with low and consistent $\mathrm{Cr} / \mathrm{Mn}$, and relatively high and variable $\mathrm{Fe} / \mathrm{Ti}$ ratio, that we have called Group B. There are also some outliers, including a tight group with a $\mathrm{Cr} / \mathrm{Mn} \approx 1.0$. This pattern could suggest that the garnets in the West Hanney Brooch derive from a single source of garnets with very variable compositions. However, this is geologically unlikely; virtually all of the garnets in the other two brooches belong to a single compositional group. This suggests that the three brooches, broadly contemporary and with related designs, share the Group A group of garnets. This would mean the Group B garnets 
are from another source. As indicated on Fig. 7, all the larger garnets in the inner two rings are Group B, along with a selection of other, smaller stones. In addition, one of the three surviving cabochon garnets from the Hanney brooch falls into this group. The implications of these patterns are discussed below.

It could be argued that there are more groups present here than just two; it can be difficult to distinguish a new group from instrumental or compositional scatters around an existing group. The garnets from Groups A and B are, nevertheless, clearly different, and provide sound evidence on which to base archaeological conclusions. Further analysis of other garnet-inlaid metalwork would be needed to demonstrate the existence (or otherwise) of other such groups.

\section{Gold alloys}

Analysis of the gold alloy elements of all three brooches was carried out where possible. The question to which the analysis was addressed was essentially whether the gold alloy elements within an individual brooch were compositionally the same and whether the different brooches had similar compositions. Gold purity and surface treatment, though important, were not considered as they are not directly relevant to this question; ${ }^{15}$ the focus of the analysis was instead on the extent to which different foils contained similar impurities. The analyses were compared by inspection of the full spectrum of each of the analyses carried out. Examples of these are shown in Figures 8 and 9 [INSERT figs. 8 \& 9 HERE].

Multiple analyses conducted on the gold alloy of one component of a single brooch showed very close agreement, as might be expected. In most cases, this is also true when different gold components from the same brooch are analysed; they too are compositionally very similar. Comparisons between the same components across the three brooches are shown in figure 8 . Once again, there is a broad similarity between the compositions of the components, but with some minor differences.

\section{Copper alloys}

The problems of analysing corroded copper alloy surfaces have been discussed above. Figure 9 shows the different analyses derived from the base plates of the three brooches. Each of the three alloys appears to be different; the Milton/V\&A brooch is richer in tin with traces of

\footnotetext{
15 Blakelock, La Niece and Fern 2016
} 
zinc, whereas both of the Milton brooches have a higher lead content than the brooch from Hanney. The analysis of further copper alloy components (i.e. the strips used to form the cellwork) revealed an apparently significant variation in the composition of similar components between the three brooches, especially in the tin and zinc content. There is thus no evidence to suggest that the copper alloys from all of the brooches, or even the pieces within one brooch, came from the same stock of metal.

\section{Discussion of results}

Detailed analysis of the craftsmanship and technology involved in the production of the three brooches has confirmed the exceptionally close relationship between the two brooches from Milton. At the same time, it has demonstrated that - despite their obvious resemblance there are significant differences with the Hanney brooch in terms of construction. It could even be argued that some of the attributes which are shared with the Hanney brooch - the gold backing foils, loops, fastenings and beaded wire - were relatively standard for disc brooches of this particular type. ${ }^{16}$ Nevertheless, the three brooches do share several significant and distinctive features, namely the rows of pentagonal garnets and, of course, their overall design, dimensions and layout, which suggest the use of shared templates.

Compositional analysis of the gold components of the brooches has revealed relatively little variation within and between them, apart from two of the four gold mounts on the Hanney brooch that appear to be replacements for lost or damaged originals. ${ }^{17}$ These are decorated with crude, plain wire filigree scrolls in contrast to the more accomplished beaded wire scrolls used on the other two mounts; they also have a higher silver content. The gridded gold backing foils are compositionally similar in all three brooches. Such foils - used to enhance the brilliance of the garnets - are thought to come from larger, pre-stamped sheets which were cut to the desired shapes. ${ }^{18}$ The close compositional similarity combined with the fact that the stamping pattern on the gold foils is the same on all three brooches - a standard grid with a line-count of 4 per $\mathrm{mm}$ - suggests that the foils from all three brooches could have been cut from the same sheet. Only 'standard' foils could be analysed as none of the 'box grid' foils found behind the larger garnets on the Hanney brooch was exposed.

\footnotetext{
16 Avent 1975; Pinder 1995

17 Hamerow 2015

18 Avent and Leigh 1977; East 1985
} 
Much work has been done to provenance the garnets used in early medieval metalwork, notably using PIXE and $\mu$-Raman spectrometry. ${ }^{19}$ This has been used to distinguish stones originating from India and Sri Lanka from those coming from Bohemia and has helped reveal the routes by which these gems reached northern Europe. These methods, however, are relatively time-consuming and costly, and the complexities involved are considerable. ${ }^{20}$ The aim of the present study, in contrast, has been to use XRF to distinguish stones that are compositionally distinct and therefore must have come from different sources, and those that came from the same source. This approach, which is relatively quick and inexpensive, can reveal the extent to which the garnets used in an item of metalwork derive from diverse sources, as might be expected if the stones were recycled, and can potentially indicate links between different artefacts.

The results for the three brooches examined in this study revealed two distinct compositional groups, i.e. garnets from two distinct sources were used, with stones from one of the two groups, Group A, being present in all three objects. The two Milton brooches contain almost exclusively Group A stones; these brooches thus display the closest similarities not only in terms of design and craftsmanship, but also of the materials used. The Hanney brooch also contains mostly Group A garnets but in addition incorporates a significant number of stones from a second group, Group B. The compositional distinction between the two groups is, furthermore, borne out by differences in the size of the garnets. On the West Hanney brooch, all of the larger garnets belong to Group B. There is also a discernible variation in colour apparent between the two groups, with nearly all of the Group A garnets on the Hanney brooch being a deep red colour, while around half of the Group B garnets have a lighter, purplish hue. There is nothing in the placement of Group A and Group B garnets, however, to indicate that garnets of different colours were deliberately selected in order to create a particular design or effect. Rather, Group B garnets appear to have been selected for their size, possibly in the absence of large Group A garnets.

These results suggest that the smiths involved in the production of these three brooches had access to a large number of garnets from the same source, i.e. Group A. The smith producing the Hanney brooch, however, appears not to have had enough Group A garnets to complete the design and so utilized some garnets from a different batch that derived from a different source. It may be that only a few batches of garnets entered England

\footnotetext{
19 Périn, Calligaro and Vallet et al 2007

20 As reviewed by Adams 2011, 16-17
} 
in the middle decades of the seventh century, when these brooches were made and when the supply of fresh garnets is known to have been in decline. ${ }^{21}$ It appears, nevertheless, that the garnets used in the upper Thames Valley brooches were not taken from a 'mixed bag' collected over many years and/or recycled from older objects.

The results of this study demonstrate the potential of a relatively simple, integrated analysis of materials and techniques to establish links between items of garnet-inlaid metalwork commissioned by early medieval elites. The study has also yielded insights into the production of high-status objects as a cultural practice and how this production was organized. It has been possible to establish that the close similarity in design between the three brooches is matched by a degree of consistency in their construction - notably the apparent use of shared templates-- and that the Hanney brooch, whose design differs somewhat from the Milton brooches, was also constructed differently and includes garnets from a different group. The compositional characteristics of the metal alloys and garnets as well as the use of shared templates suggest, nevertheless, a close connection between the workshops where the brooches were made and the families who commissioned them.

\section{Acknowledgements}

The authors are grateful to the following, without whose help this study would not have been possible: Richard Edgecumbe and Jo Whalley of the Victoria \& Albert Museum and Mark Norman, Eleanor Standley and Stephanie Ward of the Ashmolean Museum generously made the Milton brooches available for study; David Moon and Sarah Morton of Oxfordshire Museums Service facilitated access to the Hanney brooch; Sophie Beckett, Fiona Brock and Keith Rogers of Cranfield University meticulously undertook the CT scans and XRD analysis of the Hanney and Milton brooches and Ryan Brown assisted with data analysis and prepared most of the analytical graphs. George Speake, Chris Fern, Peter Hommel and Noel Adams generously shared their expertise in early medieval metalwork. We are grateful to Pieta Greaves for facilitating the examination of the Staffordshire hoard at the Birmingham Museum and Art Gallery, to John Finley Ong for his editorial assistance and to Julia Schroeder for preparing Figure 6. High definition full frame digital macro photography was undertaken by Ian R Cartwright, Institute of Archaeology, University of Oxford. All images were captured with a Nikon D810 rendering a 36.3 megapixel per image. RTi photography (Reflectance transformation imaging) was utilized to highlight surface detail.

\footnotetext{
${ }^{21}$ Hamerow 2015 and 2017
} 


\section{Bibliography}

Åberg, N 1926. The Anglo-Saxons in England, W Heffer \& Sons, Cambridge

Adams, N 2011. 'The garnet millennium: the role of seal stones in garnet studies', in C Entwhistle and N Adams (eds), Gems of Heaven: recent research on engraved gemstones in Late Antiquity, BM Research Publication 179, 10-24, British Museum, London

Anonymous, 1847. 'Archaeological intelligence', Archaeological Journal 4, 252-54

Arrhenius, B 1982. 'Technical properties as a discriminant in migration period jewellery' in L Webster (ed) Aspects of Production and Style in Dark Age Metalwork: selected papers given to the British Museum seminar on jewellery AD 500-600, 1-19, British Museum, London

Arrhenius, B 1985. Merovingian Garnet Jewellery: emergence and social implications, Almqvist \& Wiksell international, Stockholm

Avent, R 1975. Anglo-Saxon garnet inlaid disc and composite brooches, BAR Brit Ser 11, Oxford

Avent, R and Leigh, D 1977. 'A study of cross-hatched gold foils in Anglo-Saxon jewellery', Medieval Archaeology 21, 1-46

Baldwin Brown, G 1915. The Arts in Early England, John Murray, London

Bimson, M 1985. 'Dark Age garnet cutting', Anglo-Saxon Studies in Archaeology and History 4,125-28

Blair, W J 1994. Anglo-Saxon Oxfordshire, Sutton Publishing, Stroud 
Blakelock, E, La Niece, S and Fern, C 2016. 'Secrets of the Anglo-Saxon goldsmiths: analysis of gold objects from the Staffordshire hoard', Journal of Archaeological Science 72, $44-56$

Campbell, J (ed) 1991. The Anglo-Saxons, Penguin Books, London

Chadwick Hawkes, S 1974. 'The Monkton brooch', The Antiquaries Journal 54, 245-56

Chadwick Hawkes, S 1984. 'The Amherst brooch', Archaeologia Cantiana 100, 129-51

Coatsworth, E and Pinder, M 2002. The art of the Anglo-Saxon goldsmith, The Boydell Press, Woodbridge

Craddock, P, Cowell, M and Hook, D et al 2010. 'Change and stasis: the technology of Dark Age metalwork from the Carpathian Basin', Technical Research Bulletin 4, 55-65, British Museum, London

Dickinson, T 1993. 'Early Saxon saucer brooches: a preliminary overview', Anglo-Saxon Studies in Archaeology and History 6, 11-44

Domoney, K 2012. Non-destructive Hand-held X-ray Fluorescence analysis of Meissen and Vincennes-Sevres Porcelain: characterisation, dating and attribution, Unpublished PhD thesis, Cranfield University

East, K 1978. 'Backing materials in the garnet inlays and behind bronze foils on the Sutton Hoo shield', in R Bruce-Mitford The Sutton Hoo Ship Burial, vol 2: arms, armour and regalia, Appendix B, 123-26, British Museum Publications, London

East, K 1985. A study of the cross-hatched gold foils from Sutton Hoo. Anglo-Saxon Studies in Archaeology and History 4, 129-41

Evison, V 1951. 'The white material in Kentish disc brooches', Antiquaries Journal 31, 197200 
Geake, H 1997. The use of Grave-goods in conversion-period England, c 600-850, BAR Brit Ser 261, Oxford

Goodburn-Brown, D 1988. 'Metalworking tools and workshop practices: interpretation of worked metal surfaces via silicone rubber moulds', in S Olsen (ed) Scanning Electron Microscopy in Archaeology, 55-64, BAR Inter Ser 452, Oxford

Hamerow, H 2017. 'The circulation of garnets in the North Sea zone, c 400-700, in A Hilgner, S Greiff and D Quast (eds) Gemstones in the First Millennium AD: mines, trade, workshops and symbolism, 71-86, Verlag des Römisch-Germanischen Zentralmuseums, Mainz

Hamerow, H, Ferguson, C and Naylor, J 2013. 'The origins of Wessex pilot project', Oxoniensia 78, 49-70

Hamerow, H, Byard, A, Cameron, E et al 2015. 'A high-status seventh-century female burial from West Hanney, Oxfordshire', The Antiquaries Journal 95, 91-118

Hook, D and La Niece, S 2000. 'The composite disc brooch from Grave 11 and other precious metal grave-goods', in K Penn Excavations on the Norwich Southern By-Pass, 1989-91 Part II, The Anglo-Saxon cemetery at Harford Farm, Caistor St Edmund, Norfolk, 76-81, East Anglian Archaeology Report 92, Specialist Report III

Hook, D, La Niece, S and Lang, J et al 2009. 'Scientific examination of the composite discbrooch and other jewellery and associated organic material from grave 93', in C Scull Early Medieval Cemeteries at Boss Hall and Buttermarket, Ipswich, Suffolk, Society for Medieval Archaeology Monograph 27, Routledge, Abingdon

Huggett, J 1988. 'Imported grave goods and the early Anglo-Saxon economy', Medieval Archaeology 32, 63-96

Isbell, A 2015. 'Broaching the subject: the geometry of Anglo-Saxon composite brooches', MA thesis, University of Iowa, $<$ http://ir.uiowa.edu/etd/1641 $>$ (24 Feb 2016) 
Jessup, R 1950. Anglo-Saxon jewellery, Faber and Faber, London

Kendrick, T 1933. 'Polychrome jewellery in Kent', Antiquity 7, 429-52

La Niece, S 1988. 'White inlays in Anglo-Saxon jewellery', in E Slater and J Tate (eds)

Science and Archaeology, 235-46, BAR Brit Ser 196, Oxford

La Niece, S 1990. 'Silver plating on copper, bronze and brass', The Antiquaries Journal 70, $102-114$

Larson, E 1987. 'SEM-identification and documentation of tool marks and surface textures on the Gundestrup cauldron', in J Black (ed) Recent Advances in the Conservation and Analysis of Artifacts, 393-409, Summer Schools Press, London

Leahy, K 2011. 'Anglo-Saxon crafts', in H Hamerow, D Hinton and S Crawford (eds) The Oxford Handbook of Anglo-Saxon Archaeology, 440-59, Oxford University Press, Oxford

Lucy, S 2000. The Anglo-Saxon Way of Death, Sutton Publishing, Stroud

MacGregor, A 1985. Bone, Antler, Ivory and Horn, Croom Helm, London

Middleton, A, Shearman, F and Stapleton C et al 1998. 'The Guilton brooch', Jewellery Studies 8, 27-35

Périn, P, Calligaro, T and Vallet, F et al 2007. 'Provenancing Merovingian garnets by PIXE and $\mu$-Raman spectrometry', in J. Henning (ed) Post-Roman Towns, Trade and Settlement in Europe and Byzantium, vol 1, 69-76

Pinder, M 1995. 'Anglo-Saxon garnet cloisonné composite disc brooches: some aspects of their construction', Journal of the British Archaeological Association 148, 6-28

Pinder, M 2001. 'An aspect of seventh-century Anglo-Saxon goldsmithing', in M Redknap, N Edwards and S Youngs et al (eds) Pattern and Purpose in Insular Art, 133-39, Oxbow, Oxford 
Pollard, M, Bray, P and Gosden, C et al 2015. 'Characterizing copper-based metals in Britain in the first millennium AD: A preliminary quantification of metal flow and recycling', Antiquity 89, 697-713

Scull, C 2009. Early Medieval Cemeteries at Boss Hall and Buttermarket, Ipswich, Suffolk, Society of Medieval Archaeology Monograph 27, London

Speake, G 1980. Anglo-Saxon Animal Art, Oxford University Press, Oxford

Turner-Walker, G, Hamerow, H and Caple, C et al 1995. 'The gold Anglo-Saxon pendant: technical, analytical and stylistic attributes', in R Ivens Tattenhoe and Westbury: two DMVs in Milton Keynes, 397-403 and fig 142, Buckinghamshire Arch Soc, Aylesbury

Werner, A and Sax, M 1967. Report on scientific examination of an Anglo-Saxon brooch from Sarre, British Museum Research Laboratory

Whitfield, N 1990. 'Round wire in the Early Middle Ages', Jewellery Studies 4, 13-27

Whitfield, N 1998. 'The manufacture of ancient beaded wire: experiments and observations', Jewellery Studies 8, 57-86

\section{Figure captions (Main text)}

Fig 1. Left hand column: Unrestored photos of the composite disc brooches from West Hanney and Milton; Right hand column: Digitally restored images of the same objects. (Photos and digital restoration I. Cartwright, Institute of Archaeology Oxford). The Hanney Brooch, copyright Oxfordshire Museums Service; The Milton Brooch AN1836 p. 123.59 copyright Ashmolean Museum, Oxford; The Milton Brooch M.109-1939, copyright the Victoria and Albert Museum

Fig 2. Distribution map of composite disc brooches in England 
Fig 3. Composite disc brooches with copper alloy cloisons. Top row, 1-r: brooch from Monkton, Kent, (C) Ashmolean Museum, Oxford; brooch from Sarre, Kent, (C) Trustees of the British Museum; brooch from Floral Street, London, (C) Museum of London. Bottom row, 1-r: brooch from Boss Hall, Suffolk, (C) Ipswich Borough Council; brooch from Faversham, Kent, CFitzwilliam Museum, Cambridge

Fig 4. Venn diagram showing brooch attributes

1. Radius to the satellite rivets $25 \mathrm{~mm}$

2. Radius of $2^{\text {nd }}$ and $3^{\text {rd }}$ concentric rings $12.5 \mathrm{~mm}$ and $17 \mathrm{~mm}$

3. Rows of small pentagonal garnets

4. Small 4-sided garnets

5. Large 4-sided garnets

6. Gold mounts: Style II interlace

7. Gold mounts: modelled

8. Gold mounts: etched/pickled

9. Filigree wire: beaded

10. Filigree wire: round

11. Gold mounts: small rectangular

12. Gold mounts: S-scrolls

13. Gold foils: 4 lines $\mathrm{p} \mathrm{mm}$

14. Gold foils: 3.2 lines $\mathrm{p} \mathrm{mm}$, boxed grid

15. White domes: bone

16. White domes: shell

17. Base plate: convex

18. Base plate: flat

19. Safety loop on back

20. Fastening: Avent's Type 5

21. Extra plate above base plate

22. Rivets: iron

23. Rivets: copper-alloy tubes

24. White paste includes wax

25 . White paste without wax

26. Craftsmanship (gold mounts) high

27. Craftsmanship (gold mounts) medium

28. Craftsmanship (gold mounts) low

Fig 5a \& 5b. Close-ups of the composite disc brooch from West Hanney (Photo: I

Cartwright; (C) Oxfordshire Museums Service)

Fig 6. Graph plotting the ratios of $\mathrm{Cr} / \mathrm{Mn}$ against $\mathrm{Fe} / \mathrm{Ti} \mathrm{Fe} / \mathrm{Ti}$ in the garnets used in the brooches from West Hanney and Milton

Fig 7. The West Hanney brooch showing the distribution of the two garnet groups. Garnets of Group B are outlined in white 
Fig 8. Compound spectra of analyses of gold from the backing foils, filigree wire and central collar of all three brooches

Fig 9. Comparison of the copper alloy base plates used in the three brooches

\section{Figure captions, Appendix 1}

FIG. 1 Brooch sections (CT scans by S. Beckett); (a) Milton V\&A, (b) Milton Ashmolean, (c) Hanney

FIG. 2 Base-plates (CT scans by S. Beckett); (a) Milton V\&A, (b) Milton Ashmolean, (c) Hanney

FIG. 3 Back-plates (CT scans by S. Beckett); (a) Milton V\&A, (b) Milton Ashmolean, (c) Hanney

FIG. 4 Diagrams a-c: back-plates showing positions of: 1. five main rivets, 2. safety loops, 3 . catch-plates, 4. pin fixings; (a) Milton V\&A, (b) Milton Ashmolean, (c) Hanney Diagrams d-f: Milton V\&A pin hinge in plan and sections, showing 1. Back of the brooch; 2. Collar, riveted to back of brooch; 3. Hinge; 4. Loop; 5. Cylinder casing; 6. Pin

\section{Tables, Appendix 1}

TABLE 1 Anglo-Saxon composite brooches (*indicates brooch fragments reused as pendants).

TABLE 2 Dimensions of the three designs, measured in mm from CT scans 